\title{
RF-Assisted Cystectomy and Pericystectomy: A New Technique in the Treatment of Liver Hydatid Disease
}

\author{
Mustafa Sahin $^{a}$ Adil Kartal $^{\mathrm{a}}$ Rahime Haykir $^{\mathrm{b}}$ Murat Cakir $^{\mathrm{a}}$ \\ Departments of ${ }^{a}$ General Surgery and ${ }^{b}$ Radiology, Selcuk University Meram Medical Faculty, Konya, Turkey
}

\author{
Key Words \\ RF energy - Liver hydatid disease - Cystectomy • \\ Pericystectomy
}

\begin{abstract}
Background: Radiofrequency (RF) energy has been used for ablation and resection of liver tumors. Purpose: To present a new technique for the treatment of liver hydatid cyst disease. Material and Methods: Two patients with liver hydatid disease treated with RF energy cauterization and surgical resection are presented. Cystectomy was performed in a female patient aged 35 years and pericystectomy was carried out in another female patient aged 55 years using RF energy cauterization. Blood was not needed during the operation. RITA ${ }^{\circledR}$ System (RITA Model 1500 RF Generator, RITA Medical Systems, Inc., USA) was used during the procedure. Conclusion: Cystectomy and pericystectomy in liver hydatid disease can be successfully performed with the assistance of RF energy.
\end{abstract}

Copyright @ 2006 S. Karger AG, Basel

\section{Introduction}

Hydatid disease of liver is endemic in the Balkans, Mediterranean and Asian countries, and New Zealand where animal breeding is common $[1,2]$. Immigration between countries may lead to disease emergence world- wide [2, 3]. Although hydatid disease is a benign parasitic disease, studies and debates are still ongoing with respect to its treatment. Despite the various treatment methods described up to today [4-6], research is still being conducted on this issue. In the last few years, approaches such as partial cystectomy + open drainage to the peritoneal cavity and non-invasive percutaneous drainages procedures (PAIR, percutaneous aspiration irrigation reaspiration and $\mathrm{PAI}$, percutaneous aspiration and injection) have been considered among the most preferred methods [7-11]. Due to recurrence problems of the disease and due to the difficulty in the differential diagnosis resulting from residual lesions observed during the follow-up of the disease, resective surgical procedures have found application again [12-14].

In this paper, we aimed to present and discuss radiofrequency (RF)-assisted cystectomy and pericystectomy in the treatment of liver hydatid disease, performed using needles delivering RF energy.

\section{Method}

RITA $^{\circledR}$ System (RITA Model 1500 RF Generator; RITA Medical Systems, Inc., Fremont, Calif., USA) was used during the procedure. Plates were fixed under the knees of the patient's legs and a connection was established with the instrument. The material covering the outer surface of the RITA needle was peeled $4 \mathrm{~cm}$ from the distal end. The instrument was operated in $\mathrm{P}$ mode. Power was set to 100 Watt, with target heat at $100^{\circ} \mathrm{C}$. When the needle was inserted into the tissue, the procedure was started and terminated

\section{KARGER \\ Fax +4161306 1234 E-Mail karger@karger.ch} www.karger.com
C 2006 S. Karger AG, Basel 0014-312X/06/0382-0090\$23.50/0

Accessible online at: www.karger.com/esr
Dr. Mustafa Sahin

Selcuk Universitesi Meram Tip Fakultesi

Genel Cerrahi Klinigi, TR-42080 Konya (Turkey)

Tel. +90 3322236619 , Fax +90 3322236181

E-Maildrsahin@selcuk.edu.tr 

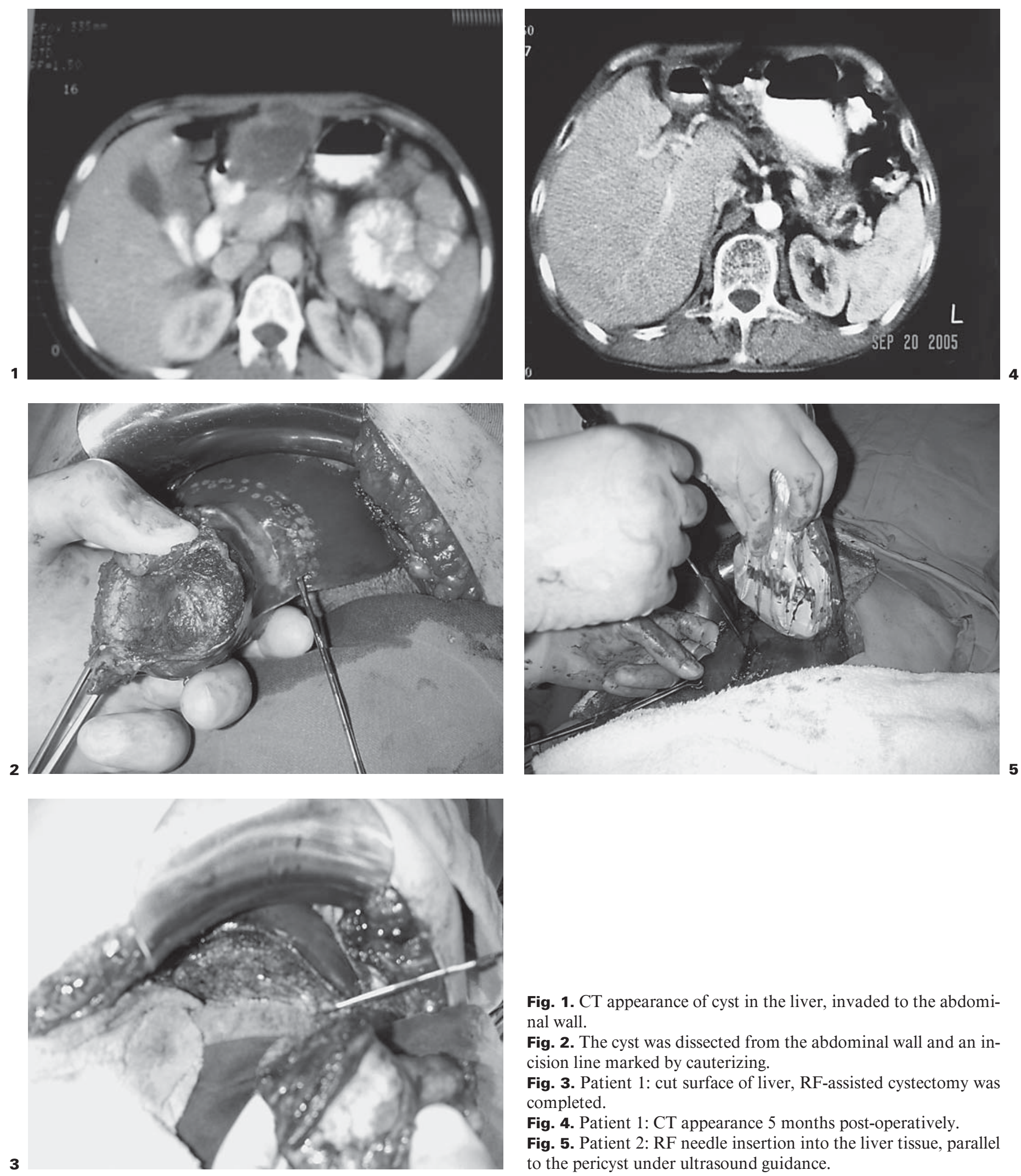

Fig. 1. CT appearance of cyst in the liver, invaded to the abdominal wall.

Fig. 2. The cyst was dissected from the abdominal wall and an incision line marked by cauterizing.

Fig. 3. Patient 1: cut surface of liver, RF-assisted cystectomy was completed.

Fig. 4. Patient 1 : CT appearance 5 months post-operatively.

Fig. 5. Patient 2: RF needle insertion into the liver tissue, parallel to the pericyst under ultrasound guidance. 
when the impedance reached 300 scale and then restarted. Areas cauterized accordingly were incised with a lancet. The procedure was continued until the liver segment containing the cyst was incised and resected completely. No major bleeding occurred during the procedure, and RF was reapplied to areas where small bleeding has occurred in order to ensure bleeding was controlled. Big vessels ( $>7 \mathrm{~mm}$ ) need to be occluded with any device (suturing, clipping, ligature, etc.).

\section{Patients}

Patient 1. A female patient aged 35 years presented with a mass localized to the epigastrium, and physical examination revealed a localized, semimobile and hard lesion. CT showed a cystic lesion of $5 \times 4 \mathrm{~cm}$ in the left lobe of the liver, invasive to the abdominal wall (fig. 1). IHA test was positive. No pathological findings were observed in other examinations. The patient was operated on under general anesthesia. The abdomen was exposed by a midline incision. After separating the lesion from the front wall of the abdomen, the peripheral area of the cyst was marked with a cauterizer (fig. 2), and the procedure was performed by inserting the RF needle into the liver tissue. Cystectomy procedure was completed by incising cauterized areas (fig. 3). No complications were observed during the operation and for 5 months during the postoperative follow-up (fig. 4).

Patient 2. A female patient aged 55 years presented with right upper quadrant pain, and ultrasonography revealed a cystic lesion of $10 \times 8 \mathrm{~cm}$ in the right lobe of the liver. CT confirmed that the lesion was a hydatid cyst. Moreover, IHA test was found to be serologically positive. No other pathological findings were detected in the hematological and biochemical parameters. The patient was operated on under general anesthesia following routine preparations. Abdomen was exposed by a right subcostal incision. After the cyst content was inactivated with hypertonic saline, cystotomy was performed and the contents of the cyst were evacuated. After the system had been prepared, RF needle was inserted into the liver, passing $0.7-1 \mathrm{~cm}$ away from pericyst and cauterized (fig. 5). Cauterized regions were incised with a lancet and the procedure was then continued. Localization of the cyst and its impact on vascular structures were determined using intraoperative US. Since a close participation at the centromedial part of the cyst with large biliary ducts and veins was detected, the procedure was terminated as a partial pericystectomy. No complications were observed during the operation and in the 4-month postoperative period.

\section{Discussion}

Various techniques have been described for the treatment of liver hydatid cysts. Almost all such surgical techniques have the common property of inactivation and evacuation of the cyst contents. The differences between the techniques arise from the removal of cyst cavity. Along with such conservative techniques as marsupialization (external drainage), cystojejunostomy partial cystectomy + omentopexy, introflexion, overlapping, partial cystectomy + opening to the peritoneal cavity, aggressive surgical techniques such as cystectomy, pericystectomy and hepatic resections have also been described $[4,6,8$, $9,13,15]$.

Recently, it has also been shown that liver hydatid cysts can be successfully treated using non-invasive, percutaneous interventions and large series have been published. Of these methods, PAIR and PAI have been widely used $[16,17]$.

Conservative surgical methods have both some advantages and disadvantages. The most important disadvantage of these methods is the remaining cyst material that causes problems in differential diagnosis in the postoperative follow-up. In addition, biliary leakage may also occur. Another important complication is the recurrence due to spreading of the disease during the evacuation of the cyst content $[4,12]$. The disadvantages of percutaneous interventions including the anaphylaxis risk, spreading, the possibility of being infected and necessity of a very long follow-up period have always made them problematic $[9,14]$.

Resective surgical methods have been considered as more extensive and aggressive surgical procedures for such a benign lesion have not been usually performed except in rare cases. But when considering all adverse effects, resective surgical interventions in the treatment of liver hydatid disease have regained popularity in recent years because of relatively easy follow-up and complete elimination of recurrence problem.

Weber et al. [18] showed that the RF energy used in the ablation of liver tumors could be used in the resection of these lesions and that the operation could be performed without bleeding and without Pringle maneuver and the operation could be completed in a shorter time. Habib et al. [19] showed that RF energy can be used for the resection of splenic mass. Based on these data, we performed an RF-assisted resective procedure in the treatment of liver hydatid disease in 2 patients. The operation was completed in both patients without any complication.

Our RF-assisted cystectomy procedure is not any different to the resective procedure performed by Weber et al. [18] in liver tumors. Liver tissue was cauterized with a RF needle at a safety distance to the cyst wall and incised without bleeding. Neither biliary leakage nor any other problems were observed during the postoperative followup period. When compared to other treatment modalities, this method has important advantages such as no need for opening cyst cavity, allowing a bloodless operation, absence of any remaining lesion and avoiding postoperative bile leakage due to the sealing provided by RF.

RF-assisted pericystectomy procedure was carried out, as in other surgical interventions, following inactiva- 
tion and evacuating of the cyst content. RF application in pericystectomy differs from cystectomy to some extent. In pericystectomy, a cauterization and an incision line parallel to the cyst cavity is followed. The procedure should be performed at a distance of $0.7-1 \mathrm{~cm}$ in order to ensure that the cyst wall is not affected by the RF energy.

Cystectomy (hepatectomy) may be preferred in small and peripherally localized cases. However, pericystectomy should be considered in cases where large-sized and centrally localized cysts require removal of a relatively large mass of liver tissue. The most important advantage of RF-assisted resection is that they do not require un- necessary removal of healthy liver. Besides, the procedure may be performed as a partial pericystectomy in major vascular formation and neighborhoods with biliary ducts, as in our case. In such a case, the biliary duct that can be opened to the cyst cavity remaining should be reviewed.

In conclusion, we suggest that both of the methods can be applied successfully in the treatment of liver hydatid cysts. These techniques will minimize the potential risk for bleeding, will decrease the spread and relevant recurrence risk as well as they will minimize biliary leakage risk and will eliminate the difficulties for differential diagnosis since the whole lesion can be removed.

\section{References}

1 Saidi F: Surgery of Hydatid Disease, ed 1. London, Saunders, 1976, pp 22-25.

-2 Amir-Jahed AK, Fardin R, Farzad A, Bakshandeh K: Clinical echinococcosis. Ann Surg 1975; 182:541-546.

-3 Kumar A, Chattopadhyay TK: Management of the hydatid disease of the liver. Postgrad Med J 1992;68:853-856.

4 Sayek I, Yalin R, Sanac Y: Surgical treatment of hydatid disease of the liver. Arch Surg 1980; 115:847-850.

$\checkmark 5$ Barros JL: Hydatid disease of the liver. Am J Surg 1978;135:597-600.

-6 Ariogul O, Emre A, Alper A, Uras A: Introflexion as a method of surgical treatment for hydatid disease of the liver. Surg Gynecol Obstet 1989;169:356-358.

-7 Yol S, Kartal A, Tavli S, Sahin M, Vatansev C, Karahan O, Belviranli M: Open drainage versus overlapping method in the treatment of hepatic hydatid cyst cavities. Int Surg 1999;84: 139-143.

-8 Mentes A, Yuzer Y, Ozbal O, Coker A, Ilter T, Musoglu A: Omentoplasty versus introflexion for hydatid liver cysts. J R Coll Surg Edinb 1993;38:82-85 $\checkmark 9$ Kama NA, Sahin M, Gocmen E, Bayrak M, Kulacoglu H, Akat AZ: The results of surgical techniques in hepatic hydatidosis: treatment with drainage versus treatment without drainage - a 6-year experience. J R Coll Surg Edinb 1998;43:254-256.

10 Khuroo MS, Dar MY, Yattoo GN, Zargar SA, Javaid G, Khan BA: Percutaneous drainage versus albendazole therapy in hepatic hydatidosis: a prospective randomized study. Gastroenterology 1993;104:1452-1459.

$\checkmark 11$ Aygun E, Sahin M, Odev K, Vatansev C, Aksoy F, Paksoy Y, Kartal A, Karahan O: The management of liver hydatid cysts by percutaneous drainage. Can J Surg 2001;44:203-209.

12 Kazez K, Sahin M, Vatansev C, Aritas Y, Aksoy F, Vatansev H: Experimentally developed secondary echinococcosis in pleural and peritoneal cavities and utility of serological tests during the follow-up. Turk J Med Sci 2000;30: 101-107.

13 Bengisu N, Saglam A, Tolu I, Akyurek N, Sahin M, Topaloglu U, Aritas Y: Omentoplasty is invalid on healing of the residual cyst cavity in the treatment of the liver hydatidosis. Turk $\mathrm{J}$ Gastroenterohepatol 1992;4:281-287.
14 Tolu I, Gulec M, Sahin M, Bengisu N, Gonen $\mathrm{O}$, Yagc1 M: The role of ultrasonography in differentiating the postoperative liver hydatid cysts. Turk Clin Res 1991;9:66-70.

15 Kartal A, Sahin M, Yol S, Belviranlı M, Karahan O, Vatansev C, Acıkgozoglu S: The management of hepatic hydatid cyst cavity by overlapping. Ann Saudi Med 1998;18:82-83.

16 Odev K, Paksoy Y, Arslan A, Aygun E, Sahin M, Karakose S, Baykan M, Arikoglu H, Aksoy F: Sonographically guided percutaneous treatment of hepatic hydatid cysts: long-term results. J Clin Ultrasound 2000;28:469-478.

17 Paksoy Y, Odev K, Sahin M, Dik B, Ergul R, Arslan A: Percutaneous sonographically guided treatment of hydatid cysts in sheep: direct injection of mebendazole and albendazole. $\mathrm{J}$ Ultrasound Med 2003;22:797-803.

18 Weber JC, Navarra G, Jiao LR, Nicholls JP, Jensen SL, Habib NA: New technique for liver resection using heat coagulative necrosis. Ann Surg 2002;236:560-563.

19 Habib NA, Spalding D, Navarra G, Nicholls J: How we do a bloodless partial splenectomy. Am J Surg 2003; 186:164-166. 